\title{
Optimization of culture conditions of Streptomyces rochei (MTCC 10109) for the production of antimicrobial metabolites
}

\author{
N. Gopi Reddy*, D.P.N. Ramakrishna \& S.V. Rajagopal
}

Department of Biotechnology, GITAM Institute of Sciences, GITAM University, Visakhapatnam, India.

\begin{abstract}
Fermentation and culture conditions were studied in shaken-flask culture to induce the production of greater amounts of antimicrobial metabolites by Streptomyces rochei (10109). Antimicrobial metabolite production started after $48 \mathrm{~h}$ incubation and reached its optimum level at $20 \%$ inoculum size at $120 \mathrm{~h}$, at which point the metabolites showed maximum antifungal and antibacterial activity against selected human pathogenic microorganisms (Candida albicans, Staphylococcus aureus and Escherichia coli). Optimal production occurred at $\mathrm{pH} 7.5$ and temperature $32^{\circ} \mathrm{C}$, with $2 \%$ glycerol and $1 \%$ peptone as the carbon and nitrogen sources respectively. The effects of adding sea water (optimum 30\%) and $\mathrm{NaCl}$ (optimum 1\%) were also evaluated.
\end{abstract}

Keywords: human pathogens

\section{Introduction}

The importance of marine sources for the discovery of novel natural products with a pharmaceutical potential has been proved during the last decade, highlighted in various reviews (Faulkner 2000; Haefner 2003; Blunt et al. 2003). More than $70 \%$ of the naturally derived antibiotics currently in clinical use are derived from marine actinomycetes (PimentelElardo et al. 2009), which play an important role among marine bacterial communities, because of their diversity and ability to produce novel chemical compounds of high commercial value (Hopwood 2007; Amador et al. 2003). They are widespread in most ecological niches (Takahashi \& Omura 2003). Actinomycetes especially Streptomyces species are a rich source of several useful bioactive natural products with potential applications (Ubukata et al. 1995; Hayakawa et al. 1996; Xue et al. 1998; Jones 2000; Manteca et al. 2008; Atta 2009; Lakshmipathy \& Kannabiran 2009) and are prolific producers of secondary metabolites, many of which have commercial importance as antibiotics, antiparasitics and antifungal agents, herbicides, pesticides, anticancer or immunosuppressive agents as well as industrially important enzymes (Curl et al. 1985; Choi et al. 1996; Osada 1998; Tskahashi \& Omura 2003; Saadoun \& Gharaibeh 2003; Maskey et al. 2003; Atta \& Ahmad 2009).

The focus on the physiology and the potential of bioactive substances of noncultivable marine microorganisms is of current problem and it becomes a great challenge to researchers to cultivate and isolate novel secondary metabolites for therapeutic applications. Improvement in the growth is carried out by manipulating the nutritional and physical parameters of the culturing conditions. Media composition plays a vital role in the efficiency and economics of the ultimate process. These not only influence the growth and metabolism of the culture, but also increase product titre and consequently process economics. The strategies that are generally adopted for selecting media composition include easy availability in the market at low cost, minimum variation from batch to batch, ability to support the growth of the organism and product formation, and limitation of production of unwanted byproducts and compounds closely related to the product of interest.

Antibiotic biosynthesis is a specific property of microorganisms and depends greatly on culture conditions. It is necessary to develop optimum conditions to make the production of an antibiotic feasible. The ability of Streptomyces cultures to form antibiotics is not a fixed property but can be greatly increased or completely lost under different conditions of nutrition

\footnotetext{
* Author for correspondence
} 
and culturing (Waksman 1961), and hence the medium constitution together with the metabolic capacity of the producing organism greatly affect antibiotic biosynthesis. Changes in the nature and type of carbon, nitrogen and phosphate sources, and trace elements, have been reported to affect antibiotic biosynthesis in Streptomyces (Barratt \& Oliver 1994; Lounes et al. 1996; Abbanat et al. 1999). Antibiotic productivity tends to decrease when metal-ion-deficient media are used and when the inocula are incubated for long periods and at high temperatures (Higashide 1984).

The present study describes the optimization of the culture conditions such as requirements of natural sea water, temperature, $\mathrm{pH}$, concentrations of $\mathrm{NaCl}$, and carbon and nitrogen sources for the production of antimicrobial metabolites. The study can be compared with other similar studies of the same (e.g. Chattopadhyay \& Sen 1997) or different species (e.g. Saurav \& Kannabiran 2010).

\section{Materials \& Methods}

The producer organism Streptomyces rochei was isolated from seawater samples collected from the Visakhapatnam coast of the Bay of Bengal. A pure culture of this strain was maintained on starch casein agar slants kept in a refrigerator at $4^{\circ} \mathrm{C}$ until used. Morphological, culture and physiological characteristics of the strain were studied using the standard methods of the International Streptomycetes Project (ISP) recommended by Shirling and Gottlieb (Mocheva et al. 2002). The strain was identified as Streptomyces rochei and deposited in the Microbial Type Culture Collection (MTCC), Chandigarh, India with accession number 10109.

For seed culture preparation, a loopful of mycelium with spores were taken from 7-dayold slant culture and used to inoculate a $250-\mathrm{ml}$ flask containing $25 \mathrm{ml}$ of seed medium broth of composition ( $\mathrm{g} \mathrm{L}^{-1}$ ) as follows: soyabean meal (10), glucose (10), $\mathrm{CaCO}_{3}(1), \mathrm{K}_{2} \mathrm{HPO}_{4}(1)$, and a mixture (50:50) of distilled water and natural seawater aged for 30 days and adjusted to $\mathrm{pH}$ 7.0. The mixture was incubated at $30^{\circ} \mathrm{C}$ for $48 \mathrm{~h}$. The production medium was prepared similarly, and 48-h-old seed culture was used as the inoculum.

Growth of Streptomyces rochei (10109) was measured as mycelium dry weight. The contents of the culture flask was filtered through a previously weighed dry Whatman No.1 filter paper, washed twice with distilled water and then the filter paper along with the mycelial mass was dried in a hot-air oven at $80{ }^{\circ} \mathrm{C}$ for $18-24 \mathrm{~h}$. The filter paper was then cooled in a desiccator and weighed. At 24-h intervals the flasks were harvested and the biomass determined in terms of total dry cell weight.

Antimicrobial metabolite production was carried out in production medium. Five $\mathrm{ml}$ of seed culture were used to inoculate a $250-\mathrm{ml}$ flask containing $50 \mathrm{ml}$ of production medium broth, which was then cultured in submerged shaken-flask fermentation and adjusted to $\mathrm{pH}$ 7.0. It was then incubated for an additional $120 \mathrm{~h}$ at $30{ }^{\circ} \mathrm{C}$ on the rotary shaker at $110 \mathrm{rpm}$. The culture broth was then centrifuged at $10,000 \mathrm{rpm}$ for $15 \mathrm{~min}$ to separate the cells from the fermented broth, and the clear supernatant broth used as the source of crude antimicrobial metabolites.

The antimicrobial activity of the fermented broth was examined against selected human pathogenic microorganisms: the fungus Candida albicans (MTCC 183) ('CA' on the figures), the gram-positive bacterium Staphylococcus aureus (MTCC 1771) ('SA' on the figures) and the gram-negative bacterium Escherichia coli (MTCC 443) ('EC' on the figures). Pathogenic microorganisms were obtained from IMTECH, Chandigarh, India. Potato dextrose broth and nutrient broth media were used for the cultivation of test fungi and bacterial species respectively, and all the cultures were kept at $4{ }^{\circ} \mathrm{C}$. Antimicrobial activity was tested by the agar-well diffusion method (Saadoun \& Muhana 2008). Wells of $6 \mathrm{~mm}$ diameter were prepared in nutrient-agar plates and the test pathogenic bacterial and fungal cultures swabbed onto the surface (Mitra et al. 2008). The wells were filled with $50 \mu$ l of crude culture 
supernatant, and the diameter of inhibition zones measured after incubation for $24 \mathrm{~h}$ at $37{ }^{\circ} \mathrm{C}$ (bacterial species) and $48 \mathrm{~h}$ at $28^{\circ} \mathrm{C}$ (fungal species).

In order to enhance the antimicrobial metabolites production, optimization of the production medium was essential. The classical method of experimentation with one factor varying at a time, with all other factors held constant at a specific level, was carried out as described by Strobel \& Sullivan (1999). The effect of the medium components on antimicrobial metabolite production in submerged flask culture was studied by removing medium components one by one and observing their effect on the production of metabolites.

In order to study the enhancement or inhibitory effect of nutrients on antimicrobial metabolite production, supplementation experiments were performed. Several sources of carbon and nitrogen were supplemented in the production medium, and the best sources were also tested for optimal antimicrobial metabolite production at different concentrations. In addition, the effects of supplements such as inoculum size, seawater and $\mathrm{NaCl}$ were studied at the optimal incubation time of $120 \mathrm{~h}$. Various inoculum sizes $(10 \%, 15 \%, 20 \%$ and $25 \% \mathrm{v} / \mathrm{v})$ were tested, as were different dilutions of seawater $(15 \%, 30 \%, 45 \%$ and $60 \%)$ with distilled water as a control. Different temperatures $\left(28,32,37,42\right.$ and $\left.50{ }^{\circ} \mathrm{C}\right)$ and $\mathrm{pHs}(6.0,7.0,7.5$, 8.0, 9.0 and 10.0) were tested, as were concentrations of $\mathrm{NaCl}(1,1.5,2,3$ and $4.5 \%)$. Various carbon sources (starch, glucose, glycerol, xylose, arabinose, sucrose, lactose, galactose, ribose, meso-inositol and citric acid) were tested to determine the best one, which was further studied at different concentrations (1,2 and 3\%) to determine the optimum. Various nitrogen sources (peptone, potassium chloride, casein, yeast extract, meat extract, ammonium chloride and sodium nitrite) were also tested, and again the best one studied at different concentrations $(1,2$ and $3 \%)$.
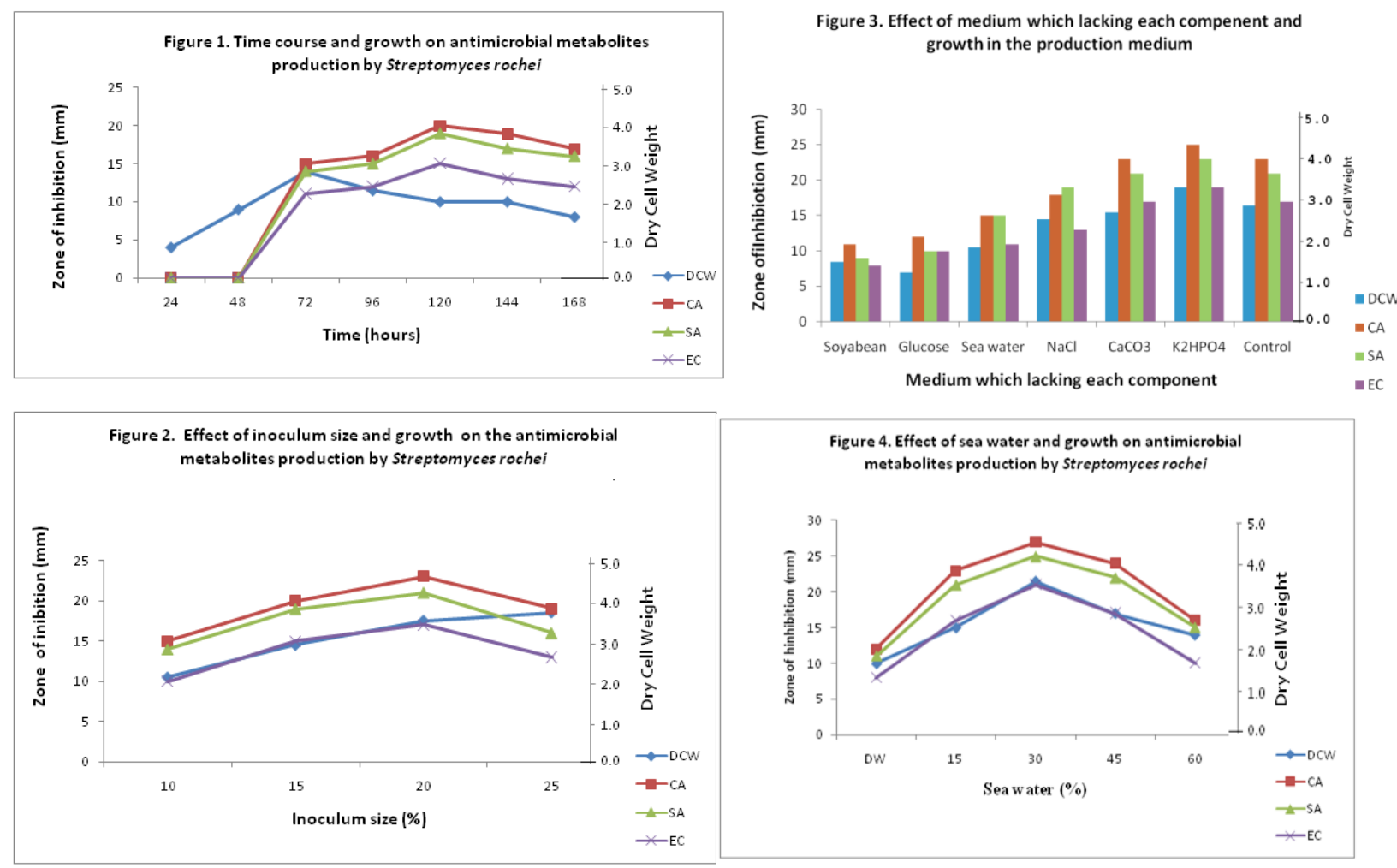

\section{Results}

On the basis of morphological, physiological and culture characteristics, and chemotaxonomic studies, the strain investigated was identified as Streptomyces (Reddy et al. 2010). It was 
further identified on the basis of $16 \mathrm{~S}$ rRNA homology studies: the gene sequence was submitted to NCBI GenBank (accession number HQ 400987) and identified as Streptomyces rochei. It has been deposited at the Microbial Type Culture Collection (MTCC), Chandigarh, India with accession number 10109.
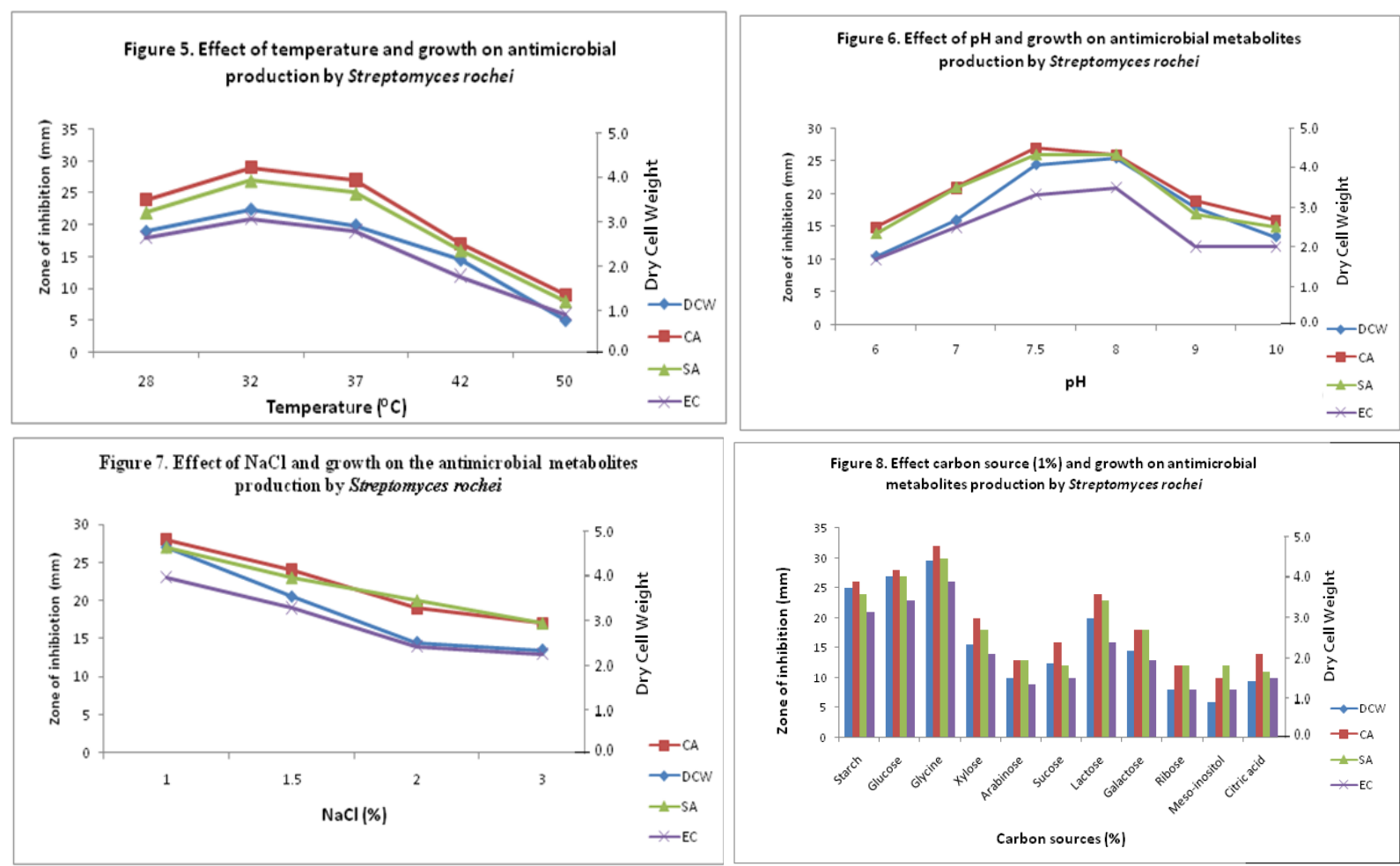

A typical time course of antimicrobial metabolite production (Fig 1) showed mycelium growth gradually increasing up to $72 \mathrm{~h}$, and then entering a stationary phase. Antimicrobial metabolite production was detected in the culture broth after $48 \mathrm{~h}$ of incubation, and reached a maximum in the late stationary phase (120 $\mathrm{h}$ incubation). Optimum inoculum size was observed at $20 \%$ $(v / v)$ (Fig 2), and further increases in the inocululm size resulted in decreased production of antimicrobial metabolites.

For optimizing the antimicrobial metabolite production, experiments with the removal and supplementation of nutrients based on single-dimension optimization were carried out. As shown in Fig 3, glucose and soybean were very important carbon and nitrogen sources, whereas natural seawater and $\mathrm{NaCl}$ were less essential. $\mathrm{K}_{2} \mathrm{HPO}_{4}$ showed a slightly inhibitory effect, and $\mathrm{CaCO}_{3}$ only helped increase growth, but did not influence the production of antimicrobial metabolites.

Tests of seawater dilutions showed that $30 \%$ was optimal for maximal production of antimicrobial metabolites (Fig 4); further dilution gradually decreased the metabolite production. The absence of sea water greatly inhibited production, clearly indicating that seawater is essential in Streptomyces rochei. $32^{\circ} \mathrm{C}$ proved to be the optimal temperature for production of metabolites (Fig 5); higher temperatures had an adverse effect on both growth and metabolite production. The $\mathrm{pH}$ of the culture broth was a significant influence on both metabolite production and mycelium growth. There was a broad range of optimum $\mathrm{pH}$ levels ranging from 7.5 to 8.0 (Fig 6), while acidic conditions supported neither growth nor metabolite production. $1 \% \mathrm{NaCl}$ was the optimum concentration production as well as growth (Fig 7); further increase in the concentration gradually decreased growth and productivity.

Antimicrobial metabolite production was greatly influenced by the nature, type and concentration of the carbon source. This strain of Streptomyces rochei was able to grow in all 
carbon sources tested (Fig 8), but maximum production was obtained in cultures supplemented with glycerol, followed by glucose and starch. $2 \%$ glycerol was the optimum concentration for metabolite production (Fig 10).

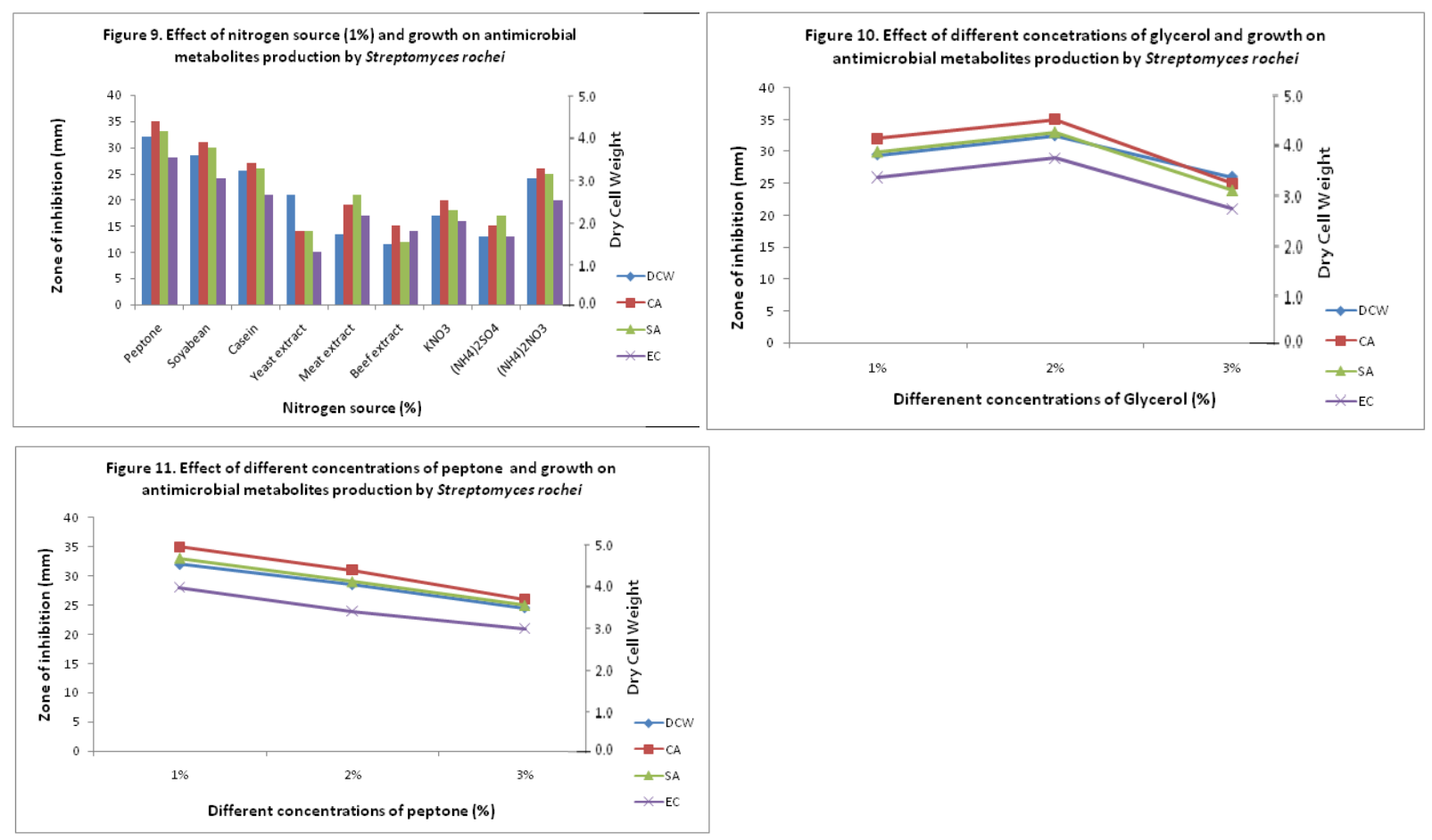

Metabolite production was also greatly influenced by the nature, type and concentration of the nitrogen source. The strain was able to grow in all the nitrogen sources tested (Fig 9), but the maximal productivity was obtained with peptone as the nitrogen source, followed by casein and $\left(\mathrm{NH}_{4}\right)_{2} \mathrm{NO}_{3} .1 \%$ peptone was the optimum concentration for productivity (Fig 11).

\section{Discussion}

Optimization of media is generally done by studying the effects of the ingredients/nutrients on growth using fermentation studies, selecting and optimizing a few parameters (Gresham \& Inamine 1986). Actinomycete cell metabolism under conditions of nutritional excess is directed towards the generation of cell mass rather than the production of secondary metabolites, and when depletion of key nutrients occurs, it shifts the cell cycle to the stationary phase and signals the transition from primary to secondary metabolism in which these bioactive metabolites are produced (Abanat et al. 19991; Abd-Allah \& El-Mehalawy 2002). In the present investigation, the time course of fermentation of Streptomyces rochei (MTTC 10109) showed mycelial growth up to $72 \mathrm{~h}$ followed by a stationary phase; antimicrobial metabolite production was detected after $48 \mathrm{~h}$ incubation, and reached optimum yields in the late exponential and stationary phase after $120 \mathrm{~h}$ incubation, indicating mainly secondary metabolism (Demain \& Fang 1995; Bibb 1996; Vineeta et al. 2008).

The inoculum size was important for metabolite production (Grag \& Neelakantan 1981; Maha et al. 2001) with an optimum at 20\% ( $/ / v)$. Marine Streptomyces are particularly attractive because they have not been extensively exploited compared to their terrestrial counterparts, and show high titers of antimicrobial metabolite production due to the diluting effect of seawater in the marine environment (Krish et al. 2010). In the present study seawater greatly enhanced growth as well as metabolite production in $S$. rochei. Environmental factors 
such as temperature, $\mathrm{pH}$ and incubation period are known to have profound influences on growth and antibiotic production in Streptomyces species (Srinivasan et al. 1991). Changes in external $\mathrm{pH}$ affect many cellular processes such as regulation and biosynthesis of secondary metabolites (Chang et al. 1991; Datta \& Kothary 1993; Sole et al. 1994; Sole et al. 1997). In the present study, maximal antimicrobial metabolite production resulted at a $\mathrm{pH}$ of 7.5 , a temperature of $32^{\circ} \mathrm{C}$ and $1 \% \mathrm{NaCl}$ concentration.

In the production of secondary metabolites, the interaction between growth metabolism and product secretion is critically influenced by growth-limiting nutrient concentrations (Kumar \& Kannabiran 2010). Optimal production has generally been achieved by cultivating organisms in media containing slowly utilized nutrient sources, or under conditions which allow a slow supply of these nutrients (Drew \& Demain 1977; Jonsbu et al. 2002). For $S$. rochei (10109), 2\% glycerol was the best carbon source for optimal metabolite production. Glycerol is known to be an important medium component for the production of antimicrobial metabolites from microorganisms (Minambres et al. 1992; Sengupta \& Paul 1992; Qureshi et al. 2001; Fukuda et al. 2005; Fguira et al. 2005; Mehdi et al. 2006). Secondary metabolite production in actinomycetes is often stimulated by slowly assimilated complex carbohydrates in the production media, and decreased when more rapidly utilized monosaccharides such as glucose are present (Bertasso et al. 2001). A possible explanation of this phenomenon is that glucose causes catabolite repression, in which the production of enzymes of secondary metabolite biosynthesis is inhibited (Drew \& Demain 1977; Iwai \& Omura 1982).

Lower concentrations of peptone $(1 \%)$ greatly favoured higher antimicrobial metabolite yield in the present investigation. Similar observations have been reported by many investigators (Khaoua et al. 1991; Mansour et al. 1996; Chattopadhyay \& Sen 1997; Vandana et al. 2008). In the present study, phosphate $\left(\mathrm{KH}_{2} \mathrm{PO}_{4}\right)$ was not favorable for metabolite production; an excessive amount of inorganic phosphate suppresses the production of antibiotics (Zinzina \& Efimova 1979; Kishimoto et al. 1996).

We conclude that the ability to produce antimicrobial metabolites changes greatly under different culture and nutritional conditions. Optimal levels of culture conditions were determined for Streptomyces rochei.

\section{Acknowledgements}

We thank the GITAM Institute for facilities used in this work.

\section{References}

Abbanat DW, Maiese D \& Greentein M (1999) Biosynthesis of pyrroidomycin by Streptomyces rugosporus LL42 DOO5; characterization of nutrient requirements. Journal of Antibiotics 52: 117-26

Abd-Allah NA \& El-Mehalawy AA (2002) Antifungal producing actinomycetes as biocontrol agents for plant pathogenic fungi. Alazhar Journal of Microbiology 58: 51-60

Amador ML, Jimeno J, Paz-Ares L, Cortes-Funes H \& Hidalgo H (2003) Progress in the development and acquisition of anticancer agents from marine sources. Annals of Oncology 14:1607-1615

Atta HM (2009) An antifungal agent produced by Streptomyces olivaceiscleroticus AZ-SH514. World Applied Science Journal 6:1495-1505

Atta MA \& Ahmad MS (2009) Antimycin-A antibiotic biosynthesis produced by Streptomyces sp. AZ-AR-262: taxonomy, fermentation, purification and biological activitites. Australian Journal of Basic Science 3:126135

Barratt EM \& Oliver SG (1994) The effects of nutrient limitation on the synthesis of stress proteins in Streptomyces lividans. Biotechnology Letters 16(12): 1231-1234

Bertasso M, Hulzenkampfer M, Zeexk A, Doll Antonia F \& Fiedler H (2001) Bahremycin A and B, novel antibiotics from streptomycete sp. TU. 4128. Journal of Antibiotics 54: 730-736

Bibb M (1996) The regulation of antibiotic production in Streptomyces coelicolor A3 (2). Microbiology 142: $1335-1344$

Blunt JW, Copp BR, Munro MHG, Northcote PTN \& Prinsep MR (2003) Marine natural products. Natural Products Report 20: 1-48 
Chang SC, Wei YH, Wei DL, Chen YY \& Jong SC (1991) Factors affecting the production of eremofortin C and PR toxin in Penicillium roqueforti. Applied Environmental Microbiology 57: 2581- 2585

Chattopadhyay D \& Sen SK. (1997) Optimisation of cultural conditions for antifungal antibiotic accumulation by Streptomyces rochei G164. Hindustan Antibiotic Bulletin 39(1-4):64-71

Choi DB, Tamura S, Park YS, Okabe M, Seriu Y \& Takeda S (1996) Efficient tylosin production from Streptomyces fradiae using rapeseed oil. Fermentation Bioengineering 82:183-186

Curl EA, Gudauskas RT, Harper JD \& Peterson CM (1985) Ecology and management of soil-borne plant pathogens. American Phytopathology Society Press, St. Paul, MN. pp. 20-23.

Datta AR \& Kothary MH (1993) Effects of glucose, growth temperature and $\mathrm{pH}$ on listeriolysin O production in Listeria monocytogenes. Applied Environmental Microbiology 59: 3495-3497.

Drew SW \& Demain AL (1977) Effect of primary metabolites on secondary metabolism. Annual Review of Microbiology 31: 343-56

Demain AL \& Fang A (1995) Emerging concepts of secondary metabolism in actinomycetes. Actinomycetologica 9: $98-117$

Faulkner DJ (2000) Highlights of marine natural products chemistry. Natural Products Report 17: 1-6

Fguira et al. (2005)

Fukuda T, Matsumoto A, Takahashi Y, Tomoda H \& Omura S (2005) Phenatic acids A and B, new potentiators of antifungal miconazole activity produced by Streptomyces sp. K03-0132. Journal of Antibiotics 58:252-259

Grag SK \& Neelakantan S (1981) Effect of culture factors on cellulase activity and protein production by Aspergillus terreus. Journal of Biotechnology \& Bioengineering 23: 1653-1659

Gresham RL \& Inamine E (ed.s) (1986) Manual of Industrial Microbiology and Biotechnology.

Haefner B (2003) Drugs from the deep: Marine natural products as drug candidates. Drug Discovery Today 8:536544

Hayakawa Y, Iwakiri T, Imamura K, Seto H \& Otake N (1985) Studies on the isotetracenone antibiotics I. Capoamycin, a new antitumor antibiotic. Journal of Antibiotics 38:957-959.

Higashide E (1984) The macrolides: properties, biosynthesis and fermentation. pp. 451-509 in Vandamme EJ (ed.) Biotechnology of industrial antibiotics. Marcel Dekker, New York.

Hopwood DA (2007) Therapeutic treasures from the deep. Nature Chemistry \& Biology 3:457-458

Iwai Y \& Omura S (1982) Cultural conditions for screening of new antibiotics. Journal of Antibiotics 35:123-41.

Jones GH (2000) Actinomycin production persists in a strain of Streptomyces antibioticus phenoxazinone synthase. Antimicrobial Agents \& Chemotherapy 44(5): 1322-1327

Jonsbu E, McIntyre M \& Nielsen J (2002) The influence of carbon source and morphology on nystatin production by Streptomyces noursei. Journal of Biotechnology 95: 133-144.

Khaoua S, Librihi A, Germain P \& Lefebvre G (1991) Cephamycin C biosynthesis in Streptomyces cattleya: nitrogen source regulation. Journal of Applied Microbiology \& Biotechnology 35: 253-257.

Kishimoto K, Park YS, Okabe M \& Akiyama S-I (1996) Effect of ferrous ion on mildiomycin production by Streptoverticillium rimofaciens. Journal of Antibiotics 49: 770-774

Krish S \& Kannabiran K (2010) Diversity and exploration of bioactive marine actinomycetes in the Bay of Bengal of the Puducherry coast of India. Indian Journal of Microbiology 50(1):76-82.

Kumar S \& Kannabiran K (2010) Antifungal activity of Streptomyces VITSVK5 spp. against drug resistant Aspergillus clinical isolates from pulmonary tuberculosis patients. Journal of Mycology \& Médicine 20: 1017

Lakshmipathy DT \& Kannabiran K (2009) Morphological, biochemical and biological studies of halotolerant Streptomyces sp. isolated from saltpan environment. American Journal of Infectious Diseases 5: 207-213

Loun'es A, Lebrihi A, Benslimance C, Lefebvre G \& Germain P (1996) Regulation of spiramycin synthesis in Streptomyces ambofaciens: effect of glucose and inorganic phosphate. Journal of Microbiology \& Biotechnology 45(1-2): 204-211

Maha AH, El-Naggar MY \& Said WY (2001) Physiological factors affecting the production of an antimicrobial substance by Streptomyces violatus in batch cultures. Egyptian Journal of Biology 3: 1-10

Mansour FA, El-Shirbiny SA \& El-Metwaly NA (1996) Demethyltetracycline biosynthesis by Streptomyces aureofaciens sub-species viridulans as influenced by medium composition. Egyptian Journal of Microbiology 31: 221-235

Manteca A, Alvarez R, Salazar N, Yague P \& Sanchez J (2008) Mycelium differentiation and antibiotic production in submerged culture of Streptomyces coelicolor. Applied Environmental Microbiology 74: 387786

Maskey RP, Helmke E \& Laatsch H (2003) Himalomycin A and bisolation and structure elucidation of new fridamycin type antibiotics from a marine Streptomyces isolate. Journal of Antibiotics (Tokyo) 56:942-949.

Mehdi RBA, Sioud S, Fguira LFB, Bejar S \& Mellouli L (2006) Purification and structure determination of four bioactive molecules from a newly isolated Streptomyces sp. TN97 strain. Process Biochemistry 41:1506-13

Minambres B, Reglero A \& Luego JM (1992) Characterization of an inducible transport system for glycerol in Streptomyces clavuligerus. Journal of Antibiotics 45(2): 269-277 
Mitra A, Santra SC \& Mukharjee J (2008) Distribution of actonmycetes, their antagonistic behavior and the physio-chemical characteristics of the world tidal mangrove forest. Applied Microbial Biotechnology 80: 685-695

Mocheva P, Tishkov S, Dimitorova N, Chipeva V, Nikolova SA \& Bogatzevska N (2002) Characteristics of soil actinomycetes from Antarctica. Journal of Culture Collection 3: 3-14

Osada H (1998) Actionmycetes: how fascinating microorganisms. Actinomycetologia 12: 85-88.

Pimentel-Elardo SM, Scheuermayer M, Kozytska S \& Hentschel U (2009) Streptomyces axinellae sp.nov., isolated from the Mediterranean sponge Axinella polypoides (Porifera). International Journal of Systematic \& Evolutionary Microbiology 59: 1433-1437

Qureshi A, Mauger JB, Cano RJ, Galazzo JL \& Lee MD (2001) MF-EA-705 $\alpha$ \& MF-EA-705 $\alpha \beta$, new metabolites from microbial fermentation of a Streptomyces sp. Journal of Antibiotics 54:1100-1103.

Reddy et. al (2010)

Saadoun I \& Gharaibeh R (2003) The Streptomyces flora of the Badia region of Jordan and its potential as a source of antibiotics against antibiotic-resistant bacteria. Journal of Arid Environments 53:365-371

Saadoun I \& Muhana A (2008) Optimal production condition, extraction, partial purification and characterization of inhibitory compound(s) produced by Streptomyces Ds-104 isolate against multi-drug-resistant Candida albicans. Current Trends in Biotechnology \& Pharmacology 2: 402-420.

Saurav K \& Kannabiran K (2010) Diversity and optimization of process parameters for the growth of Streptomyces VITSVK9 spp. isolated from Bay of Bengal, India. Journal of Natural and Environmental Sciences 1(2): 56-65

Sengupta S \& Paul AK (1992) Nutritional conditions for the germination of Streptgalbus 5ME-13 spores. Acta Biotechnologica 12(3): 225-228.

Strobel RJ \& Sullivan GR (1999) Experimental design for improvement of fermentation. pp 80-93 in Demain AL \& Davies JE (eds) Manual of industrial microbiology and biotechnology. ASM Press, Washington.

Sole M, Francia A, Rius N \& Lorén JG (1997) The role of pH in the "glucose effect" on prodigiosin production by non-proliferating cells of Serratia marcescens. Letters in Applied Microbiology 25: 81-84

Srinivasan MC, Laxman RS \& Deshpande MV (1991) Physiology and nutritional aspects of actinomycetes: an overview. World Journal of Microbiology \& Biotechnology 7: 171-84.

Takahashi Y \& Omura S (2003) Isolation of new actinomycete strains for the screening of new bioactive compounds. Journal of General \& Applied Microbiology 49: 141-154.

Ubukata M, Shiraish N, Kobinata K, Kudo T, Yamaguchi I, Osada H \& Isono K (1995) RS-22A and C: new macrolide antibiotics from Streptomyces violaceusniger. Taxonomy, fermentation, isolation and biological activities. Journal of Antibiotics 48(4): 289-292.

Vandana Praveen C, Tripath KM \& Vinod Bihari (2008) Studies on optimum fermentation conditions for Actinomycin-D production by two new strains of Streptomyces spp. Medical \& Chemical Research 17: 114122

Vineeta Singh C, Tripath KM \& Vinod Bihari (2008) Production, optimization and purification of an antifungal compound from Streptomyces capoamus MTCC 8123. Medical \& Chemical Research 17: 94-102

Waksman SA (1961) The actinomycetes. Vol. 2: Classification, identification and description of genera and species. Williams \& Wilkins Co., Baltimore.

Xue Y, Zhao L, Liu HW \& Sherman DH (1998) A gene cluster for macrolide antibiotic biosynthesis in Streptomyces venezuelae: architecture of metabolic diversity. Proceedings of the National Academy of Sciences USA 95(21): 12111-12116

Zinzina ML \& Efimova TP (1979) Effect of inorganic phosphate on levorin biosynthesis and on the mycelial make up of Streptomyces levoris. Antibiotiki 24: 656-659. 
الملخص العربى

[Streptomyces rochei (MTCC 10109)] تهيئة الظروف المثلي لاستنبات بكتريا ستربتوميسيس روشيكي لإنتاج نواتج أيض مضادة للميكروبات.

$$
\text { جوبي ريدي*، راماكريشنا \& راجاجوبال }
$$

قسم التقنية الحيوية، معهد جيتام للعلوم، جامعة جيتام، فيساكاباتتام، الهند الملخص العربي

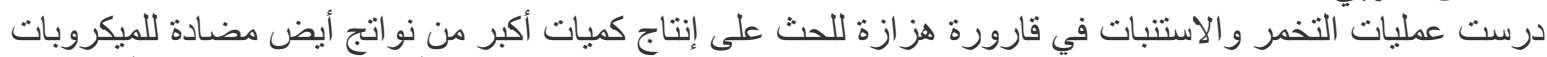

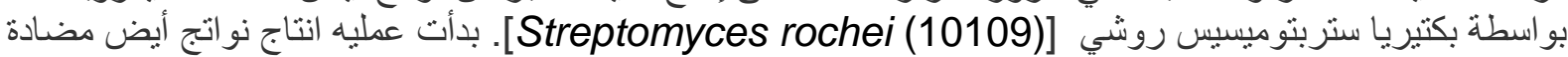

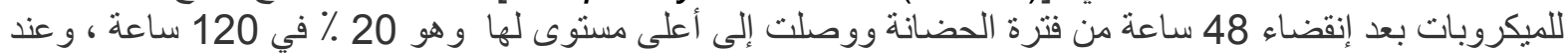

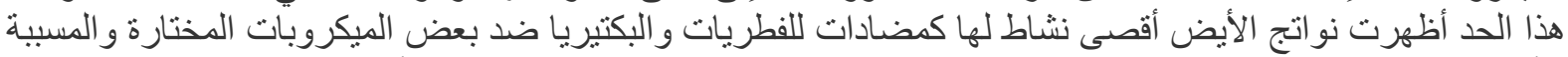

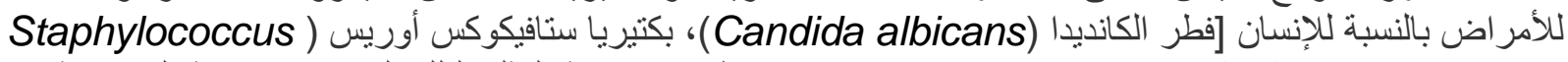

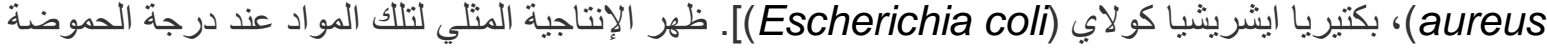

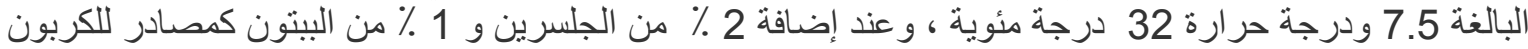

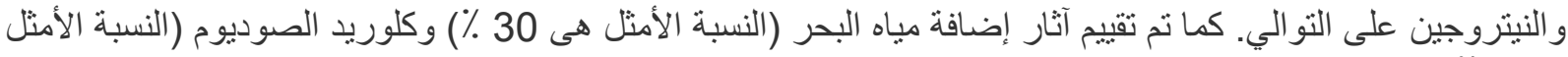

